THURSDAY, SEPTEMBER I2, IgI 2.

\section{THERMODYNAMICS OF THE} ATMOSPHERE.

Thermodynamik der Atmosphäre. By Dr. A. Wegener. Pp. viii +331. (Leipzig: J. A. Barth, I9Ir.) Price II marks.

THE progress of a science depends upon the intellectual calibre of the men who pursue it: that determines what shall be written for them as well as by them. It is therefore significant for meteorology that a text-book on the thermodynamics of the atmosphere should be added to a collection recently enriched by treatises on meteorological optics and on the foundations of dynamical meteorology. Special phases of the subject have been treated at some length by Helmholtz, Hertz, von Bezold, and others, but their papers are scattered among different scientific journals, rarely accessible in a single library. Dr. Wegener's treatise, which has been written with the object of giving a systematic account of the existing knowledge and methods, should therefore be generally welcomed.

In an introductory chapter the author deals with the constitution of the atmosphere, and discusses in interesting fashion the extreme heights at which various optical phenomena, aurora, meteors, and zodiacal light appear. He finds that in all cases the values lie roughly between 70 and $100 \mathrm{~km}$., or in the layer in which the nitrogen atmosphere is changing to the hydrogen atmosphere. After an account of the thermodynamics of an ideal gas and its application to a consideration of the precise proportions in which different gases exist at different heights, he indulges in some speculation about the existence of a hypothetical gas, geocoronium, above the hydrogen atmosphere. Such speculation is out of place in a text-book, and the same criticism applies to the statement that the stratosphere extends from $\mathrm{Ir}$ to $70 \mathrm{~km}$. There is no evidence as to the upper limit of the temperature conditions characteristic of the stratosphere.

In the third section the different phases of water vapour, the condensation on nuclei, and the formation of crystals are discussed thoroughly and comprehensively.

The fourth and fifth sections, which comprise rather more than two-thirds of the book, are undoubtedly the most valuable parts of the work. In them the author treats of the thermodynamics of adiabatic changes and of the physics of clouds respectively. The effect of the condensation of water vapour in diminishing the vertical temperature gradient for air rising adiabatically is imporNO. 2237, VOL. 90] tant both in the general circulation and in local disturbances, and it is usually put forward as the explanation of the Föhn. The cooling of the air which rises on the windward side of the mountains is influenced by the condensation and precipitation of the water which it contains. This air descends on the lee side, where there is no moderating effect on the vertical temperature gradient, and is consequently hot and dry. Dr. Wegener deduces, from the fact that the average vertical gradient is less than that corresponding to the adiabatic gradient either for saturated or for dry air, that the rising of the air on the windward side actually exerts a moderating influence on the Föhn.

$\Lambda$ very full account is given of "inversions," i.e. cases in which the temperature remains constant or increases with increasing altitude. Their connection with waves and wave-clouds is discussed at length, and the form of the surface between currents of different densities and velocities is made the subject of mathematical investigation. A chapter is devoted to the stratosphere. The different types of the temperature-height curve between the troposphere and stratosphere are illustrated by an excellent diagram derived by Schmauss from a consideration of the results obtained at Munich. In the discussion of the meteorological conditions in the stratosphere itself it is assumed that the relative humidity at the base of the stratosphere, the region of minimum temperature, is $5^{\circ}$ per cent. As there is no process by which the nitrogen-oxygen atmosphere is "dried" except by the precipitation of water condensed by cooling, it is not easy to see how a relative humidity of $5^{\circ}$ per cent. could be obtained at the place of minimum temperature, where diffusion and convection would both tend to produce saturation.

The discussion of clouds is excellent. It includes a note on the rate of fall of drops and its connection with the passage from cloud to rain. The photographs of the different forms of clouds, some of which were taken from balloons above the clouds, are well reproduced, and add considerably to the educational value of the descriptive matter and the theorctical discussion.

Dr. Wegener has performed a signal service in producing a good book on a branch of the subject which had not previously been dealt with systematically. The work as a whole loses by the deliberate exclusion of radiation, which is fundamentally and indissolubly connected with the application of thermodynamic considerations to the problems which confront the meteorologist every day. The author regards it, however, as a subject for separate treatment. 